\title{
Factors contributing towards patient's choice of a hospital clinic from the patients' and managers' perspective
}

Mohammadkarim Bahadori ${ }^{1}$, Ehsan Teymourzadeh ${ }^{1}$, Ramin Ravangard ${ }^{2}$, Ali Nasiri ${ }^{3}$, Mehdi Raadabadi ${ }^{4}$, Khalil Alimohammadzadeh ${ }^{5}$

${ }^{1}$ Health Management Research Center, Baqiyatallah University of Medical Sciences, Tehran, Iran

${ }^{2}$ School of Management and Medical Information Sciences, Shiraz University of Medical Sciences, Shiraz, Iran

${ }^{3}$ School of Health Management and Information Sciences, Iran University of Medical Sciences, Tehran, Iran

${ }^{4}$ Health Services Management Research Center, Institute for Futures Studies in Health, Kerman University of Medical Sciences, Kerman, Iran

${ }^{5}$ Department of Health Services Management, Tehran North Branch, Islamic Azad University, Tehran, Iran

Type of article: Original

\begin{abstract}
Introduction: Given the competitive nature of the health market and the multiplicity of factors that may contribute towards patient's choices of a hospital, patients' needs and preferences for a hospital must be considered in the planning and decision making of hospitals and health care organizations. This study aimed to identify the factors that contribute to patient's choices of a clinic and the importance of each factor.

Methods: A mixed-method approach was used to collect quantitative and qualitative data in two phases. The study was conducted in a hospital clinic in 2014. Qualitative data were collected by face-to-face semi-structured interviews of a sample of 22 managers and heads of outpatient wards. The self-administered questionnaire designed for this study collected quantitative data from a stratified random sample of 381 patients referred to this clinic. The qualitative data were analyzed by a system of coding, while parametrical statistical analyses were conducted to analyze the quantitative data using the independent-samples t-test and ANOVA in SPSS software, version 21.0.

Results: The qualitative data indicated that there were 21 factors that may contribute to patient's choices of a clinic, and these factors were classified into six categories, i.e., facilities and physical assets, physicians and employees, location and place, services, price, and promotion. Among the 16 questions studied in the quantitative questionnaire, the highest and lowest means were related to "appropriate clinic environment" $(2.47 \pm 0.58)$ and "advertising through TV and radio, the Internet, newspapers, etc." $(1.77 \pm 0.75)$, respectively. There were significant associations between "having experienced and responsive personnel, including physicians and employees" and the patient's gender and frequency of referrals, between "belonging to the Armed Forces" and the patient's age and frequency of referrals, between "advertising through TV and radio, the Internet, newspapers, etc." and shifts and frequency of referrals, between "inadequate facilities and poor quality of services provided in other health care organizations of the Armed Forces" and "adornment and good behavior of staff" and shifts ( $<$ $0.05)$.

Conclusion: The most significant contributing factors to attract patients were the "physicians and employees," and "the clinic's environment." Therefore, it is essential for clinic managers and heads of outpatient wards to focus on and strengthen these two factors. Also, since the means of the factors were better in the morning shift, the employees should perform their duties properly and consistently in all shifts.
\end{abstract}

Keywords: factors, choice, patient, military, clinic

\section{Introduction}

Health care organizations have undergone major changes over time to meet the specific conditions of each period. Various changes have altered scientists' views of the health care system, ad these changes include the rapid growth

\section{Corresponding author:}

Mehdi Raadabadi: Health Services Management Research Center, Institute for Futures Studies in Health, Kerman University of Medical Sciences, Kerman, Iran. Tel: +98.3536261000, Email: Mehdiraadabadi@gmail.com

Received: December 11, 2015, Accepted: March 29, 2016, Published: May 2016 iThenticate screening: March 29, 2016, English editing: April 17, 2016, Quality control: April 25, 2016

(C) 2016 The Authors. This is an open access article under the terms of the Creative Commons Attribution-NonCommercialNoDerivs License, which permits use and distribution in any medium, provided the original work is properly cited, the use is non-commercial and no modifications or adaptations are made. 
of health care costs and technologies, the increase in the complexity of health care processes, and the increase in competition among organizations that provide health care services (1). Therefore, these organizations are required to develop and implement plans for attracting more patients to ensure their survival and success. One of the most important ways to achieve these goals is to improve the quality of services provided by enhancing all medical processes, because the quality of service is a main determinant of the choice of health care providers $(2,3)$. Similarly, patients' expectations and preferences must be considered, and the quality of services must be improved based on their opinions and comments $(4,5)$. When patients have a good perception of the quality of health care services provided by a hospital and their opinions and beliefs are considered, they will probably return themselves, and their relatives and friends will come to that hospital as well (6). The concept of quality is different when viewed from the different perspectives of providers and patients. Therefore, in order to assess the quality of services, each viewpoint should be measured appropriately, and the appropriate prioritization of the factors that influence patients' preferences should be considered (7). Although the quality of services depends largely on the standards of the medical staff's performance, the patients' preferences recently have been found to be a significant factor (8). Consequently, paying attention to patients' opinions and preferences is one of the factors that have made health care organizations successful since the 1990s (9). Since 1980, in many Western countries, paying attention to the patients' preferences and choices in health care markets has been known as the most important reform, and, currently, it is considered to be an important component of successful health policy (10-12). High-quality services may result in attracting new patients and retaining existing patients, and they strengthen patient-provider relationships (13). Furthermore, improving the quality of health care services, patient-centeredness, and paying attention to the patients' needs and preferences seem to be necessary for the patients' treatment. Therefore, conducting research studies to determine patients' preferences for the services they receive has become common. Patient-centeredness is defined as a response to patients' needs, and its outcome is the tendency towards values that are important to patients, thereby resulting in the improvement of the quality of the services provided $(14,15)$. Apart from being a morally good thing to include patients' preferences, doing so may lead towards improvement in providing health care and access to sustainable and permanent care methods. This is very important, especially for patients who have different needs and preferences than other patients (16). The importance of attracting patients to hospitals and health care organizations may generate various benefits, such as increased patients' satisfaction, which may yield other referrals to the same hospital in the future. Additionally, recognizing which services have not been provided acceptably over time may help the hospital's managers adopt measures to overcome the problems associated with these services (17). York and McCarthy (2011) found that patients' satisfaction and consideration of their desires and needs are essential elements of marketing, and their acceptance and popularity has been increasing in the health care sector (18). Research has shown that several factors influence patient's choice of a hospital, such as fees, available facilities, employees' behavior (19), the hospital's reputation $(19,20)$, the network participation and the hospital's market competition (21), the physical environment $(19,20,22-27)$, how to provide and customize services (20), quality of services $(28,29)$, hospital's location and accessibility $(30,31)$, and the variety of services $(21,32,33)$. Most studies of patients' preferences when selecting a hospital have been conducted in public or private hospitals in which the majority of patients have had either social security insurance or Iran Health Insurance and private medical insurance coverage. The researchers of the present study did not find any similar study conducted in a military hospital. Also, because the majority of patients admitted to a military hospital have Armed Forces Insurance coverage, they do not pay exorbitant fees for medical services. This is a significant difference between patients referred to military hospitals and patients who are referred to public or private hospitals. The strength of this study was the investigation of service providers' viewpoints on the patients' reasons for selecting a hospital. This topic has not been paid much attention in other studies that only considered the patients' preferences. Given the multiplicity of factors that may contribute to a patient's choice of a hospital clinic, studying patients' preferences and determining the factors that are important to them in choosing a hospital clinic comprises part of the major plans of health care organizations. Thus, the aim of this study was to determine these factors and their individual importance.

\section{Material and Methods}

\subsection{Study setting and general methods}

In this study, we used a mixed-method approach of collecting both quantitative and qualitative data during January and March 2014. In Tehran Province, there are nine hospitals affiliated with the Islamic Republic of Iran's Army (AJA), three hospitals affiliated with the Iranian Revolutionary Guards Islamic Revolution (IRGC), and two hospitals affiliated with the Iran Police Forces (NAJA). All patients voluntarily can select any one of the military hospitals' clinics, and the factors that influence their choice differ depending on various factors, one of which is the hospital's location. Given that the majority of the military hospitals are in the middle of the city, they are in similar situations in terms of patients' access. Furthermore, the advantages of the studied hospital were that it was outside of 
the traffic plan and had access to the major highways of the city. The selected clinic includes 15 thematic clinic wards (including nutrition counseling, genetic counseling, obesity, headaches, and sleep disorders), pediatric, internal medicine, nephrology, cardiovascular, neurologic, eye, orthopedic, surgery, gynecology, ENT, skin, anesthesia, dental, and other (legal medicine, rehabilitation, ICU, and radiotherapy). . In this clinic, 250 physicians work in three shifts (morning, afternoon, and evening) six days a week and provide required services to the patients. There is no cost for services provided for patients who are covered by insurance provided by the Iranian Revolutionary Guards Islamic Revolution (IRGC), and these patients and their families do not pay any charges for receiving services. Also, in this hospital, patients covered by this medical insurance have higher priorities for arranging appointments and taking turn.

\subsection{Qualitative phase}

A purposive sampling technique was used to recruit a heterogeneous group of clinic managers and heads of outpatient wards. Data collection and sampling continued until data saturation was reached so that no new information emerged during the face-to-face interviews. This study sought to gather the overall views of the clinic's key informants on the factors that might attract patients to the clinic for services. Face-to-face, semi-structured interviews were conducted to collect in-depth information. A purposive sample of 22 managers and heads of outpatient wards that satisfied the eligibility criteria and who consented to participate were interviewed individually. The inclusion criteria were a minimum of five years' experience, having a key role in the studied wards, and volunteering freely to participate. The qualitative data were collected using audio-taped, face-to-face, semistructured interviews with open-ended questions. The interviewees were asked the following questions: "In your opinion, why do patients select this clinic to receive services?" and "What and which characteristics may attract patients to this clinic?" In order to give more depth to the interviews and avoid ambiguity, the following questions were asked: "Will you please explain further?" and "Would you please give me an example?" Each interview lasted 20 to 45 minutes based on the level of the interviewee's interest and participation. The face-to-face, semi-structured interviews were conducted by the researcher who visited the interviewees' workplaces for prior coordination. The transcriptions of the interviews were done by two researchers, and they were reviewed and approved by the interviewees. Dependability was enhanced by audio-tape recording of the interviews, which then immediately were transcribed verbatim. The interviewer took notes during the interviews. Data analysis was guided by conventional techniques. The transcribed data were checked and confirmed by the clinic's manager who had close interactions with the interviewees and knew them well. The transcriptions of the interviews and the related codes and categories that emerged were validated by the interviewees to ensure the credibility of the data that were collected and to confirm their authenticity. The interviewer managed to develop a trustful relationship with the interviewees, which enhanced their confidence in expressing their opinions. Conformability was assured by the audit trail, the researcher's impartiality, and peer review of the interviews, coding, and categorization of the similar codes for comparison between the understanding of the researcher and the actual perceived meaning of the interviewees. Conventional content analysis extracts the objective content available in the textual data and categorizes the direct and clear data of participants' transcriptions (34-35). In the present study, the conventional content analysis of qualitative results was performed in the following eight steps:

1) The interviews were transcribed.

2) The transcriptions were read several times to code the issues more precisely.

3) The categories were continuously compared and became inductive.

4) Part of the text was coded and the categories again were agreed. And then, the data were organized.

5) All of the text was coded.

6) The dependability of texts and the coding of transcriptions were controlled.

7) The relationships between categories were determined, and the overt and covert concepts were reviewed.

8) All of the steps mentioned above were reported completely.

\subsection{Quantitative phase}

The target population in this phase included all patients who had been referred to the clinic. The statistical power was computed assuming that $\alpha=0.05, \mathrm{p}=\mathrm{q}=0.5$, and $\mathrm{d}=0.05$. On average, referral to the clinic consisted of 4,000 patients per month or about 50,000 patients per year. Therefore, a sample size of 381 patients was determined to be an appropriate sample size for the study. This sample was selected from the different wards of the clinic using stratified sampling proportional to size and simple random sampling method using a table of random numbers. The respective inclusion criteria were the patients' willingness to participate in the study and their initial familiarity with the clinic's environment and provision of facilities. Quantitative data were collected by a questionnaire based on the 
factors identified in the qualitative data and the literature review. The content validity of this questionnaire was confirmed through the expertise of the respective professors (Content Validity Ratio: CVR $=0.75$ ). Also, its reliability was confirmed by performing test-retest reliability analysis so that the 12 questionnaires were completed by 12 patients, and, after a week, the same patients completed the questionnaires again, and the Cronbach's alpha reliability coefficient was calculated $(\alpha=0.83)$, which confirmed the questionnaire's reliability. The first part of the questionnaire consisted of the socio-demographic information of the patients, such as age, gender, marital status, status of insurance coverage, education level, wards, and shifts. The second part incorporated a set of 16, threepoint, Likert-form questions. A three-point Likert scale was used to determine the patients' reasons for selecting the hospital, whereby 1 refers to low, 2 as middle, and 3 as high, because answering the questions of a three-point Likert scale was easier than other types for patients, and they could respond to them smoothly. The questionnaires were distributed in three shifts, including the morning, evening, and night shifts. Before handing out the questionnaires, the patients were reminded of the aims of the study. For patients who were illiterate, the questions were read to them, and the questions were marked by the researcher based on the patients' responses. Because the patients were stressed by arranging an appointment and waiting to see the physicians, we gave them the questionnaires after they had seen their physicians. The data collected from the questionnaires completed by the patients were analyzed using SPSS 21.0 through parametric inferential statistical tests, including the independent-samples t-test and one-way analysis of variance (ANOVA). The values of $p<0.05$ were considered to be statistically significant. Given that patients did not have enough time to do an interview with the researchers and usually were uncomfortable due to their illnesses the use of interviews to collect the required data was not suitable. However, an open question was placed at the end of the questionnaire so that they could mention the other reasons for choosing that hospital's clinic. However, in this study, none of the participants provided any additional information in the open question. Institutional and ethical approval to conduct this study was granted by the Vice Chancellor for Research of Baqiyatallah University of Medical Sciences, as well as by the manager of the clinic. During both the quantitative and qualitative phases, informed consent was obtained from all participants, and confidentiality and anonymity were maintained.

\section{Results}

In the qualitative phase, 22 managers of the various clinic wards were studied (males: $n=19$; females: $n=3$ ) with a mean age of 35 . After conducting the interviews, there were 21 factors that the managers thought influenced the patient's choice of the clinic. These were classified into six categories, i.e., facilities and physical assets ( 2 factors), physicians and employees (4 factors), location and place ( 2 factors), services ( 5 factors), price (4 factors), and promotion (4 factors) (Table 1). In the quantitative phase, the response rate was $91.3 \%(\mathrm{n}=348)$. The results showed that most of the patients were males (61.1\%), and married (68.6\%). Most of them had armed forces family insurance (20.1\%), referred more than once (70.7\%), referred from Tehran (39.7\%), and in the evening shift (61.5\%) (Table 2). Among the 16 questions, the highest and lowest means were related to "appropriate clinic environment" $(2.47 \pm 0.58)$ and "advertising through TV and radio, internet, newspapers, etc." (1.77 \pm 0.75$)$, respectively (Table $3)$.

Table 1. Factors that influenced patient's choice of the clinic as perceived by managers and heads

\begin{tabular}{|l|l|}
\hline Factors & Variables \\
\hline Facilities and physical assets & Appropriate clinic environment, Good facilities and equipment \\
\hline Physicians and employees & $\begin{array}{l}\text { Having experienced and responsive personnel, being responsive to possible } \\
\text { errors, scientific management of the clinic in recent years, having good physicians }\end{array}$ \\
\hline Location and place & Having a strategic location in Tehran, proximity of the clinic to the hospital \\
\hline Services & $\begin{array}{l}\text { Providing high quality services in the clinic, providing various services in a day, } \\
\text { having all medical disciplines (specialty and subspecialty) in the clinic, offering } \\
\text { boarding services, using a system for queuing patients properly in all wards }\end{array}$ \\
\hline Price & $\begin{array}{l}\text { Cheaper free tariffs on visits and para-clinical services than private clinics and } \\
\text { offices, low-cost services for veterans and the families of the armed forces and } \\
\text { martyrs, being a non-commercial clinic, and promoting a patient-centered culture }\end{array}$ \\
\hline Promotion & $\begin{array}{l}\text { The hospital's reputation and being a famous hospital, obtaining the top rankings } \\
\text { among other centers in recent years, direct and indirect advertisements and } \\
\text { promotions, the audience of the hospital }\end{array}$ \\
\hline
\end{tabular}

1: Providing24-hour services; 2: People who receive their required services from the hospital 
Table 2. Demographic characteristics of patients

\begin{tabular}{|c|c|c|c|c|c|}
\hline \multicolumn{2}{|l|}{ Variables } & $\mathrm{n}(\%)$ & \multicolumn{2}{|l|}{ Variables } & $\mathrm{n}(\%)$ \\
\hline \multirow{7}{*}{$\begin{array}{l}\text { Age Group } \\
\text { (year) }\end{array}$} & $10-20$ & $46(13.2)$ & \multirow{10}{*}{$\begin{array}{l}\text { Insurance } \\
\text { Type }\end{array}$} & Employed in Armed Forces & $55(15.8)$ \\
\hline & $21-30$ & $120(34.48)$ & & Retired from Armed Forces & $35(10.06)$ \\
\hline & $31-40$ & $77(22.13)$ & & Armed Forces Family & $70(20.11)$ \\
\hline & $41-50$ & $46(13.22)$ & & $\begin{array}{l}\text { Employed in Other Armed } \\
\text { Forces }\end{array}$ & $58(16.67)$ \\
\hline & $51-60$ & $38(10.92)$ & & Armed Forces2 Family & $38(10.92)$ \\
\hline & $61-70$ & $7(2.01)$ & & Soldiers of Armed Forces & $20(5.75)$ \\
\hline & No Response & $14(4.02)$ & & $\begin{array}{l}\text { Soldiers of in Other Armed } \\
\text { Forces }\end{array}$ & $12(3.45)$ \\
\hline \multirow[t]{3}{*}{ Gender } & Male & $230(66.09)$ & & $\begin{array}{l}\text { Having Other Insurance } \\
\text { Types }\end{array}$ & $34(9.77)$ \\
\hline & Female & $115(33.05)$ & & Uninsured & $24(6.9)$ \\
\hline & No Response & $3(0.86)$ & & No Response & $2(0.57)$ \\
\hline \multirow{3}{*}{$\begin{array}{l}\text { Marital } \\
\text { Status }\end{array}$} & Single & $104(29.88)$ & \multirow{3}{*}{$\begin{array}{l}\text { Frequency of } \\
\text { Referrals }\end{array}$} & First Time & $88(25.29)$ \\
\hline & Married & $227(65.23)$ & & More than Once & $246(70.69)$ \\
\hline & No Response & $17(4.89)$ & & No Response & $14(4.02)$ \\
\hline \multirow[t]{4}{*}{$\begin{array}{l}\text { Referred } \\
\text { from }\end{array}$} & $\begin{array}{l}\text { Distant cities of } \\
\text { Tehran }\end{array}$ & $109(31.32)$ & \multirow[t]{4}{*}{ Shifts } & Morning & $112(32.19)$ \\
\hline & $\begin{array}{l}\text { Cities close to } \\
\text { Tehran }\end{array}$ & $96(27.59)$ & & Evening & $214(61.49)$ \\
\hline & Tehran & $138(39.66)$ & & Night & $13(3.73)$ \\
\hline & No Response & $5(1.43)$ & & No Response & $9(2.59)$ \\
\hline
\end{tabular}

Table 3. Mean and SD of factors that influenced the patient's choice of clinic

\begin{tabular}{|c|c|c|c|c|c|}
\hline \multirow[t]{2}{*}{ Questions } & \multicolumn{3}{|c|}{$\%$ of Patients' Responses } & \multirow[t]{2}{*}{ Mean } & \multirow[t]{2}{*}{ SD } \\
\hline & Low & Middle & High & & \\
\hline Appropriate clinic environment & 4.60 & 43.68 & 51.72 & 2.47 & 0.58 \\
\hline $\begin{array}{l}\text { Having experienced and responsive personnel including } \\
\text { physicians and employees }\end{array}$ & 6.04 & 58.62 & 35.34 & 2.29 & 0.57 \\
\hline $\begin{array}{l}\text { Inadequate facilities and poor quality of services provided in other } \\
\text { health care organizations of the Armed Forces }\end{array}$ & 16.38 & 50.00 & 33.62 & 2.17 & 0.68 \\
\hline $\begin{array}{l}\text { Being a specialty and subspecialty clinic and having the majority } \\
\text { of clinical and para-clinical services }\end{array}$ & 6.32 & 44.83 & 48.85 & 2.43 & 0.61 \\
\hline Good and modern facilities & 8.34 & 48.56 & 43.10 & 2.35 & 0.62 \\
\hline More suitable visits and services costs & 13.22 & 44.25 & 42.53 & 2.29 & 0.68 \\
\hline Having responsive managers & 16.38 & 50.86 & 41.38 & 2.16 & 0.68 \\
\hline Having trust in the clinic physicians & 10.63 & 49.71 & 39.66 & 2.29 & 0.64 \\
\hline Advertising through TV and radio, Internet, newspapers, etc. & 42.24 & 38.22 & 19.54 & 1.77 & 0.75 \\
\hline Recommending this clinic to you by the relatives and friends & 22.41 & 49.14 & 28.45 & 2.06 & 0.71 \\
\hline $\begin{array}{l}\text { The existence of a regular and systematic management system in } \\
\text { the clinic }\end{array}$ & 17.53 & 51.44 & 31.03 & 2.14 & 0.68 \\
\hline Belonging to the Armed Forces & 13.79 & 43.97 & 42.24 & 2.28 & 0.69 \\
\hline Placed outside of the traffic plan and easy access to the clinic & 15.52 & 47.99 & 36.49 & 2.21 & 0.69 \\
\hline Adornment and good behavior of staff & 11.78 & 50.29 & 37.93 & 2.26 & 0.65 \\
\hline $\begin{array}{l}\text { The good behavior of physicians and spending enough time to } \\
\text { visit the patients by them }\end{array}$ & 8.91 & 52.30 & 38.79 & 2.07 & 0.70 \\
\hline $\begin{array}{l}\text { Compliance with the Entebagh plan and respecting the patients' } \\
\text { privacy }\end{array}$ & 8.91 & 52.30 & 38.79 & 2.30 & 0.62 \\
\hline
\end{tabular}

1: A Persian name for an Iranian plan 
There were significant associations between "having experienced and responsive personnel including physicians and employees" and the patients' gender and frequency of referrals; between "belonging to the Armed Forces" and the patients' age and frequency of referrals; between "Advertising through TV and radio, Internet, newspapers, etc." and shifts and frequency of referrals Armed Forces" and "adornment and good behavior of staff" and shifts $(\mathrm{p}<0.05)$. However, there were no significant associations between the factors that affected the patient's choices of the clinic and their type of insurance (Table 4).

Table 4. Associations between the patient's choice of the clinic and their demographic characteristics

\begin{tabular}{|l|l|l|l|l|l|}
\hline Questions & p-values & \multicolumn{4}{l|}{} \\
\cline { 2 - 6 } & Age & Gender & $\begin{array}{l}\text { Type of } \\
\text { Insurance }\end{array}$ & $\begin{array}{l}\text { Frequency } \\
\text { of referrals }\end{array}$ & Shifts \\
\hline Appropriate clinic environment & 0.23 & 0.829 & 0.559 & 0.654 & 0.088 \\
\hline $\begin{array}{l}\text { Having experienced and responsive personnel } \\
\text { including physicians and employees }\end{array}$ & 0.40 & $<0.001$ & 0.348 & 0.013 & 0.829 \\
\hline $\begin{array}{l}\text { Inadequate facilities and poor quality of services } \\
\text { provided in other health care organizations of the } \\
\text { Armed Forces }\end{array}$ & 0.40 & 0.510 & 0.271 & 0.866 & $<0.001$ \\
\hline $\begin{array}{l}\text { Being a specialty and subspecialty clinic and having } \\
\text { the majority of clinical and para-clinical services }\end{array}$ & 0.50 & 0.428 & 0.960 & 0.702 & 0.181 \\
\hline Good and modern facilities & 0.14 & 0.396 & 0.912 & 0.008 & 0.171 \\
\hline More suitable visits and services costs & 0.89 & 0.515 & 0.926 & 0.057 & 0.146 \\
\hline Having responsive managers & 0.60 & 0.723 & 0.976 & 0.828 & 0.697 \\
\hline Having trust in the clinic physicians & 0.31 & 0.88 & 0.196 & 0.105 & 0.247 \\
\hline $\begin{array}{l}\text { Advertising through TV and radio, Internet, } \\
\text { newspapers, etc. }\end{array}$ & 0.26 & 0.931 & 0.902 & 0.035 & $<0.001$ \\
\hline $\begin{array}{l}\text { Recommending this clinic to you by the relatives and } \\
\text { friends }\end{array}$ & 0.75 & 0.239 & 0.077 & 0.865 & 0.440 \\
\hline $\begin{array}{l}\text { The existence of a regular and systematic management } \\
\text { system in the clinic }\end{array}$ & 0.24 & 0.149 & 0.075 & 0.522 & 0.284 \\
\hline Belonging to the Armed Forces & 0.03 & 0.775 & 0.053 & 0.017 & 0.390 \\
\hline $\begin{array}{l}\text { Placed outside of the traffic plan and easy access to the } \\
\text { clinic }\end{array}$ & 0.21 & 0.371 & 0.742 & 0.090 & 0.328 \\
\hline Adornment and good behavior of staff & 0.89 & 0.321 & 0.897 & 0.450 & 0.014 \\
\hline $\begin{array}{l}\text { The good behavior of physicians and spending enough } \\
\text { time to visit the patients by them }\end{array}$ & 0.78 & 0.316 & 0.496 & 0.929 & 0.066 \\
\hline $\begin{array}{l}\text { Compliance with the Entebagh plan and respecting the } \\
\text { patients' privacy }\end{array}$ & 0.32 & 0.101 & 0.579 & 0.686 & 0.028 \\
\hline
\end{tabular}

\section{Discussion}

Today, different countries evaluate the status of their daily and routine health care and are seeking to change the status of their health system and provide more appropriate services to the patients. Hospitals are the center of gravity of providing care and should be studied from different aspects, as the most important centers of providing health care (36). However, the present status of today's hospitals indicates the patients' dissatisfaction with the services provided and the failure to meet their expectations (37). Therefore, the patients' expectations and preferences should be considered to meet their needs and expectations. Consequently, this study aimed to investigate the factors that contribute to patient's choice of a clinic in a military hospital. The quantitative findings from patients demonstrated that the "appropriate clinic environment" had the highest mean. Similarly, the qualitative data from managers and heads identified the "appropriate clinic environment" as one of the factors influencing patient's choices of the clinic. Douglas and Douglas (2005), Akinci et al. (2004), Gotlieb (2000), and Woodside et al. (1988) found that physical appearance and hospital facilities and design were among the factors that affected the patient's choices of a hospital (38-41). This is because patients in their first encounter are faced with the hospital environment, the appearance of hospital space, which may attract them. However, the patients' good physical condition also may improve their mental image and comfort. Similarities were found in both the quantitative and qualitative findings, whereby the factors such as, "having experienced and responsive personnel including physicians and employees;" "being a specialty and subspecialty clinic and having the majority of clinical and para-clinical services;" "good and modern 
facilities;" "having trust in the clinic physicians;" and "adornment and good behavior of staff" had the next priorities. These findings were supported by research whereby Lux and colleagues (29) showed that various factors, such as private physicians, recommendations from family and friends, quality of care, and the level of access to a hospital were factors that affected patient's choices of a hospital, which was consistent with the results of both the qualitative and quantitative data of this study. Similarly, Miller and colleagues found that various factors, such as the hospital's reputation, good design for a hospital, appropriate hospital environment, having adequate parking, and having high standards of cleanliness had effects on patient's choice of a hospital (42). Additionally, Baldwin and Shaw identified similar factors, such as maintaining the standards of cleanliness, the appropriate method of management, respecting patients' privacy and individuals' personality as the factors that influence patient's choice of a hospital (43). Green and colleagues considered various factors, such as having adequate parking, the hospital's ancillary facilities, and the hospital's reputation as the factors that affect patient's choices of a hospital (44). In this study, "being a specialty and subspecialty clinic and having the majority of clinical and para-clinical services" and "providing various services in a day" were found as effective factors in both qualitative and quantitative findings. Similarly, Roh and colleagues found that providing various and additional services were found to influence patient's choice of a hospital (21). Furthermore, this study showed that "cheaper free tariffs on visits and para-clinical services than private clinics and offices" and "more suitable visit and services costs" were attractive to patients. These are consistent with the findings of Goldsteen and colleagues who considered some factors, such as the number of services provided and low cost of services as the effective factors (32). "Having experienced and responsive personnel including physicians and employees" had significant associations with the patients' gender and frequency of referrals. Therefore, male patients and those who had been referred more than once considered the physicians and staff as factors that affect patient's choice of a clinic. This may be due to the existing higher number of male patients referred to the clinic than females and the greater number of male employees in the clinic who were reported to communicate better with patients. There were no significant associations between the factors that influenced patient's choice of clinic and their type of insurance. This may be because, in this clinic, the costs of visits and services were low, and the majority of patients had Armed Forces Insurance. However, the results of a study conducted by Sepehri et al. in Vietnam showed that the type of insurance had different effects on the patient's choice of a hospital and their average length of stay in the hospital (45). Also, no significant associations were found between "belonging to the Armed Forces" and patients' age and frequency of referrals. Therefore, older patients and referrals to the clinic more than once were associated with "belonging to the Armed Forces," indicating that patients referred to the clinic had considered this as an effective factor. Moreover, "the good behavior of physicians and spending enough time to visit the patients by them" and "compliance with the Entebagh plan and respecting the patients' privacy" were not significantly associated with shifts of work. The means of these factors were higher in the morning shift, indicating that these factors were followed better and respected more by the clinic employees in the morning shift than in other shifts.

The means of all the patients' perceived factors, except advertisement, were found higher, indicating that all these factors contributed significantly to the patient's choice of the clinic. Therefore, changing the management approach of health care organizations to the management of patients' preferences is necessary. This approach considers the patient to be a key element, and provision of individualized, appropriate, and desirable services is essential. The managers of every health care organization in competition with other health care organizations should give priority to patients' satisfaction, and attention must be given to patients' preferences in their strategic plans in order to maintain attraction to and retention of patients in the clinic. This generates the importance of conducting research studies on the assessment and evaluation of hospital and clinic services from the patients' perspectives, as well as investigating patients' preferences in the health care marketing industry. Since the findings from qualitative data are not generalizable, measures were taken to enhance the trustworthiness of data, which helped to explain further the quantitative phase of the study. The special rules and regulations of military clinic and hospital restricted data collection, such as referral of patients only on certain days of the week, no permission to enter female wards, and distributing and completing questionnaires under the ward secretary's supervision. Some managers and heads had limited time for the interviews, which might have lessened the collection of in-depth data. Thus, appointments were given to the managers, and they were reminded frequently to enhance the response rate and the quality of data collection. Some patients refused to complete the questionnaire, which limited the generalization of the results. However, they were inevitably replaced by other patients with the same characteristics. 


\section{Conclusions}

The results of this study showed that the "physicians and employees" and the clinic's environment contributed highly towards attracting patients to the military clinic. Therefore, it is essential that these two factors be considered at strategic levels. Also, clinic managers and heads should focus on, emphasize, and strengthen these two factors in the daily functions of the clinic. Also, the managers and heads should make appropriate plans to improve the clinic's environment and increase the required facilities and proportion of the number of employees to better match the number patients in the clinic. Since the means of these factors were better in the morning shift, it is recommended that the employees should perform their duties properly and consistently in all shifts.

\section{Acknowledgments:}

This article was extracted from a research project supported financially by the Vice Chancellor for Research of Baqiyatallah University of Medical Sciences, grant No. 2125. The researchers thank the heads and staff of the clinic in which the study was conducted, as well as the patients for their kind cooperation with the researchers in collecting and analyzing the data.

\section{Conflict of Interest:}

There is no conflict of interest to be declared.

\section{Authors' contributions:}

All authors contributed to this project and article equally. All authors read and approved the final manuscript.

\section{References}

1) Sibbel R, Urban C. Agent-based modeling and simulation for hospital management. Cooperative agents. 2001: 183-99. doi: 10.1007/978-94-017-1177-7 11.

2) Jenkinson C, Burton JS, Cartwright J, Magee $\bar{H}$, Hall I, Alcock C, et al. Patient attitudes to clinical trials: development of a questionnaire and results from asthma and cancer patients. Health Expect. 2005; 8(3): 244-52. doi: 10.1111/j.1369-7625.2005.00335.x

3) Merle V, Germain JM, Tavolacci MP, Brocard C, Chefson C, Cyvoct C, et al. Influence of infection control report cards on patients' choice of hospital: pilot survey. J Hosp Infect. 2009; 71(3): 263-8. doi: 10.1016/j.jhin.2008.11.025. PMID: 19147258 .

4) Torres EJ, Guo KL. Quality improvement techniques to improve patient satisfaction. Int J Health Care Qual Assur Inc Leadersh Health Serv. 2004; 17(6): 334-8. doi: 10.1108/09526860410557589. PMID: 15552388.

5) Davis BA, Kiesel CK, McFarland J, Collard A, Coston K, Keeton A. Evaluating instruments for quality: testing convergent validity of the consumer emergency care satisfaction scale. J nurs care qual. 2005; 20(4): 364-8. doi: 10.1097/00001786-200510000-00013. PMID: 16177589.

6) Lee MA, Yom YH. A comparative study of patients' and nurses' perceptions of the quality of nursing services, satisfaction and intent to revisit the hospital: A questionnaire survey. Int J Nurs Stud. 2007; 44(4): 545-55. doi: 10.1016/j.ijnurstu.2006.03.006. PMID: 16687147.

7) Bjørngaard JH, Ruud T, Garratt A, Hatling T. Patients' experiences and clinicians' ratings of the quality of outpatient teams in psychiatric care units in Norway. Psychiatr Serv. 2007; 58(8): 1102-7. doi: 10.1176/ps.2007.58.8.1102. PMID: 17664522.

8) Soufi G, Belayachi J, Himmich S, Ahid S, Soufi M, Zekraoui A, et al. Patient satisfaction in an acute medicine department in Morocco. BMC health serv res. 2010; 10(1): 149. doi: 10.1186/1472-6963-10-149. PMID: 20525170.

9) Schulmeister L, Quiett K, Mayer K. Quality of life, quality of care, and patient satisfaction: perceptions of patients undergoing outpatient autologous stem cell transplantation. Oncol Nurs Forum. 2005; 32(1): $57-67$. doi: 10.1188/05.ONF.57-67. PMID: 15660144.

10) Anell A. The monopolistic integrated model and health care reform: the Swedish experience. Health Policy. 1996; 37(1): 19-33. doi: 10.1016/0168-8510(96)00821-4. PMID: 10158941.

11) Øvretveit J. Informed choice? Health service quality and outcome information for patients. Health policy. 1996; 37(2): 75-90. doi: 10.1016/S0168-8510(96)90053-6. PMID: 10162644.

12) Vrangbaek K, Bech M. County level responses to the introduction of DRG rates for "extended choice" hospital patients in Denmark. Health Policy. 2004; 67(1): 25-37. doi: 10.1016/S0168-8510(03)00085-X. PMID: 14726005.

13) Zarei A, Arab M, Froushani AR, Rashidian A, Tabatabaei SMG. Service quality of private hospitals: The Iranian Patients' perspective. BMC health serv res. 2012; 12(1): 31. doi: 10.1186/1472-6963-12-31. 
14) van Empel IW, Dancet EA, Koolman XH, Nelen WL, Stolk EA, Sermeus W, et al. Physicians underestimate the importance of patient-centredness to patients: a discrete choice experiment in fertility care. Hum Reprod. 2011; 26(3): 584-93. doi: 10.1093/humrep/deq389. PMID: 21227936.

15) Hart M. Improving out-patient clinic waiting times: methodological and substantive issues. Int $\mathrm{J}$ Health Care Qual Assur. 1995; 8(6): 14-22. doi: 10.1108/0952686951009881316. PMID: 10165401.

16) Dwight-Johnson M, Lagomasino IT, Aisenberg E, Hay J. Using conjoint analysis to assess depression treatment preferences among low-income Latinos. Psychiatr Serv. 2004; 55(8): 934-6. doi: 10.1176/appi.ps.55.8.934.

17) Yaghoubi M, Agharahimi Z, Karimi S, Javadi M. Factors Affecting Patients' Preferences in Choosing a Hospital Based on the Mix Marketing Components in Isfahan. Hakim. 2011; 14(2): 106-14.

18) York AS, McCarthy KA. Patient, staff and physician satisfaction: a new model, instrument and their implications. Int J Health Care Qual Assur. 2011; 24(2): 178-91. doi: 10.1108/09526861111105121. PMID: 21456492.

19) Mosadeghrad AM. Patient choice of a hospital: implications for health policy and management. Int $J$ Health Care Qual Assur. 2014; 27(2): 152-64. doi: 10.1108/IJHCQA-11-2012-0119. PMID: 24745140.

20) Pawlush GG. Health care marketing minicase. J Health Care Mark. 1981; 1(4): 49-52. PMID: 10254220.

21) Roh CY, Lee KH, Fottler MD. Determinants of hospital choice of rural hospital patients: the impact of networks, service scopes, and market competition. J Med Syst. 2008; 32(4): 343-53. doi: 10.1007/s10916008-9139-7. PMID: 18619098.

22) Wisniewski M, Wisniewski H. Measuring service quality in a hospital colposcopy clinic. Int J Health Care Qual Assur Inc Leadersh Health Serv. 2005; 18(2-3): 217-28. doi: 10.1108/09526860510594776. PMID: 15974517.

23) Crow R, Gage H, Hampson S, Hart J, Kimber A, Storey L, et al. The measurement of satisfaction with healthcare: implications for practice from a systematic review of the literature. Health Technol Assess. 2002; 6(32): 1-244. doi: 10.3310/hta6320. PMID: 12925269.

24) Rahmqvist M. Patient satisfaction in relation to age, health status and other background factors: a model for comparisons of care units. Int J Qual Health Care. 2001; 13(5): 385-90. doi: 10.1093/intqhe/13.5.385.

25) Danielsen K, Garratt AM, Bjertnaes OA, Pettersen KI. Patient experiences in relation to respondent and health service delivery characteristics: a survey of 26,938 patients attending 62 hospitals throughout Norway. Scand J Public Health. 2007; 35(1): 70-7. doi: 10.1080/14034940600858615. PMID: 17366090.

26) Campbell J, Ramsay J, Green J. Age, gender, socioeconomic, and ethnic differences in patients' assessments of primary health care. Qual Health Care. 2001; 10(2): 90-5. doi: 10.1136/qhc.10.2.90. PMCID: PMC1757978.

27) Quintana JM, González N, Bilbao A, Aizpuru F, Escobar A, Esteban C, et al. Predictors of patient satisfaction with hospital health care. BMC health serv res. 2006; 6(1): 102. doi: 10.1186/1472-6963-6-102. PMCID: PMC1579213.

28) Habtom GK, Ruys P. The choice of a health care provider in Eritrea. Health policy. 2007; 80(1): $202-17$. doi: 10.1016/j.healthpol.2006.02.012. PMID: 16647156.

29) Lux MP, Fasching P, Schrauder M, Löhberg C, Thiel F, Bani M, et al. The era of centers: the influence of establishing specialized centers on patients' choice of hospital. Arch gynecol obstet. 2011; 283(3): 559-68. doi: 10.1007/s00404-010-1398-0. PMID: 20180128.

30) Adams EK, Wright GE. Hospital choice of Medicare beneficiaries in a rural market: why not the closest? J Rural Health. 1991; 7(2): 134-52. doi: 10.1111/j.1475-6773.2004.00324.x. PMID: 10116774.

31) Luft HS, Garnick DW, Mark DH, Peltzman DJ, Phibbs CS, Lichtenberg E, et al. Does quality influence choice of hospital? JAMA. 1990; 263(21): 2899-906. doi: 10.1097/00006254-199010000-00015. PMID: 2110985.

32) Goldsteen RL, Falcone DJ, Broyles RW, Goldsteen K, Reilly BJ. Local factors affecting the tendency to bypass local hospitals for inpatient mental health care: an exploratory analysis. J Rural Health. 1994; 10(2): 89-96. doi: 10.1111/j.1748-0361.1994.tb00215.x. PMID: 10134717.

33) Phibbs CS, Mark DH, Luft HS, Peltzman-Rennie DJ, Garnick DW, Lichtenberg E, et al. Choice of hospital for delivery: a comparison of high-risk and low-risk women. Health serv res. 1993; 28(2): 201. PMID: 8514500, PMCID: PMC1069930.

34) Tezak B, Chan A. Nurturing the seeds of learning: a professional development initiative for hospital-based nurse educators. J Nurses Staff Dev. 2005; 21(3): 110-4. 
35) Sandelowski M. Whatever happened to qualitative description? Res Nurs Health. 2000; 23(4): 334-40. doi: 10.1002/1098-240X(200008)23:4<334::AID-NUR9>3.0.CO;2-G. PMID: 10940958.

36) Cueto M. The origins of primary health care and selective primary health care. Am J Public Health. 2004; 94(11): 1864-74. doi: 10.2105/AJPH.94.11.1864. PMCID: PMC1448553.

37) Barekatain, M, Maracy MR, Hassannejad R, Hosseini R. Factors associated with readmission of patients at a university hospital psychiatric ward in iran. Psychiatry journal. 2013; 1-5. doi: 10.1155/2013/685625.

38) Douglas CH, Douglas MR. Patient-centred improvements in health-care built environments: perspectives and design indicators. Health Expect. 2005; 8(3): 264-76. doi: 10.1111/j.1369-7625.2005.00336.x. PMID: 16098156.

39) Akinci F, Esatoglu AE, Tengilimoglu D, Parsons A. Hospital choice factors: a case study in Turkey. Health Mark Q. 2004; 22(1): 3-19. doi: 10.1300/J026v22n01_02.

40) Gotlieb JB. Understanding the effects of nurses, patients' hospital rooms, and patients' perception of control on the perceived quality of a hospital. Health Mark Q. 2000; 18(1-2): 1-14. doi: 10.1300/J026v18n01_01.

41) Woodside AG, Nielsen RL, Walters F, Muller GD. Preference segmentation of health care services: the old-fashioneds, value conscious, affluents and professional want-it-alls. J Health Care Mark. 1988; 8(2): 14-24. PMID: 10287901.

42) Miller L, May D. Patient choice in the NHS: how critical are facilities services in influencing patient choice? Facilities. 2006; 24(9/10): 354-64. doi: 10.1108/02632770610677637.

43) Baldwin E, Shaw C. Buildings. Patient choice. Pick and mix. Health serv j. 2005; 115(5940): 38. PMID: 15828092.

44) Green J, McDowall Z, Potts HW. Does Choose \& Book fail to deliver the expected choice to patients? A survey of patients' experience of outpatient appointment booking. BMC Med Inform Decis Mak. 2008; 8(1): 36. doi: 10.1186/1472-6947-8-36. PMID: 18673533, PMCID: PMC2529277.

45) Sepehri A, Simpson W, Sarma S. The influence of health insurance on hospital admission and length of stay--the case of Vietnam. Soc Sci Med. 2006; 63(7): 1757-70. doi:10.1016/j.socscimed.2006.04.029. PMID: 16766108 . 